\title{
Study on Kilns' Origin of a Black-Glazed Tea-Calix with Oil Droplets
}

\author{
Tao $\mathrm{Ma}^{1,2 *}$ \\ ${ }^{1}$ Department of Archaeology and Cultural Relics, Nanjing University, Nanjing, China \\ ${ }^{2}$ Ningbo Museum, Ningbo, China
}

Submission: February 15, 2019; Published: February 27, 2019

*Corresponding author: Tao Ma, Department of Archaeology and Cultural Relics, Nanjing University, Nanjing \& Ningbo Museum, Ningbo, China

\begin{abstract}
The author has been involved in sorting out and reporting the unearthed relics from the ruins located in the northeast of Chengdu Tianfu Square from October 2014 to January 2015. During this period, the author has noticed a unique black-glazed tea-calix with oil droplets numbered 2012CTDTN02W02 (3):1. In the published Report of Archaeological Excavation at the Ancient Ruins of Northeastern Tianfu Square, Chengdu[R], the author has classed it as Type C Jian kiln tea-calix. Afterwards, with further research, the author has found that it is incorrect to class this unique black-glazed tea-calix with oil droplets as Jian kiln. Recently, the author has got an incomplete porcelain from Huairen County in Shanxi province. After a comparative analysis on the mentioned two porcelain by digital versatile microscope, XRF and Raman spectrometer, it is shown that two porcelain enjoyed a high similarity. Thus, the two porcelain was proved to be of the same kind and same origin, which indicates that this unique black-glazed tea-calix with oil droplets should be produced in Huairen county of Shanxi province. Not only does this paper testify the good sale of porcelain of Huairen kiln in Jin Dynasty in Chengdu, but also prove that there should be open a new chapter for the status of Huairen kiln in the history of Chinese porcelain. It provides a scientific basis for studying the trade and culture between song and Jin Dynasties.
\end{abstract}

Keywords: Chengdu Tianfu Square; The black-glazed tea-calix with oil droplets; Jian kiln; Huairen kiln

\section{Introduction}

It is not that particularly mature when doing research on the origin of ancient ceramics [1], especially those based on natural science methods in China [2], so it may lead to some errors in the archaeological study [3]. In 2013, there excavated an incomplete black-glazed tea-calix with oil droplets in the northeast of Chengdu Tianfu Square. In the former excavation report, the author has classed its origin as Jianzhou kiln. However, further studies have found that this judgment is not accurate. So detailed analysis with optical microscope, X-ray fluorescence spectrometer, Raman spectrometer, and some other latest scientific instruments has been under conducting. And the results show that the origin should be in elsewhere.

The black-glazed porcelain, just as the celadon ware, enjoys a long producing history. The earliest black-glazed porcelain specimen is a black-glazed pot made in Eastern Han Dynasty (AD101) which has been unearthed in Danyang of Jiangsu province in 1973. There enjoyed a great number of black-glazed porcelain of the Southern Dynasties in East Jin excavated in Jiangsu province and Zhejiang province. And numerous kilns in the northern part of the Tang Dynasty produced white porcelain as well as black-glazed porcelain. After the Northern Song Dynasty, many black-glazed porcelains have been produced. Among the known two Song Dynasties kilns, more than $1 / 3$ are found to be black-glazed porcelain with no typical regional characteristics, which had become a popular commodity in both north and south China, especially the black-glazed tea-calix. There even existed several kilns only to produce the black-glazed tea-calix.

Calix, a kind of household utensils which is smaller than bowl, can also be called as "ou" or "wan" (the same as bowl) in the documents of Song dynasty. In Song dynasty, people are likely to add some rites while enjoying the tea, and tea competition has gained an increasing popularity since then. Drinking tea was not merely the physiological needs of quenching one's thirst, but a social behavior with most people as dignitaries, scholars, and even common people. Jianzhou Kiln was in Houjing and Chizhong villiage of Shuiji town, Jiangyang city of Fujian province which belonged to Jianzhou, and there came the name of the Jianzhou kiln. This was an important place where produced black-gazed tea-calix with oil droplets, and the provided tea-calix for tea competition were of the highest quality among the current findings. Jianzhou Kiln was first produced in the late Tang dynasty, and then became prosperous in Song dynasties. Till now, numerous kiln sites have been found: Luhuaping, Niupilun, Anweishan, Yingchangqian, Daluhoumen, Yuantoukeng and so on. The tea-calix produced here has been dominated in Song dynasty and has profound influences on the contemporary kiln sites that produced black-gazed tea-calix. 
Jianzhou Kiln is not the only one to produce the blackgazed tea-calix with oil droplets. Other kilns as Ding kiln, Hebi kiln, Linfen kiln, and Jizhou kiln possessed high production. In Southern Song dynasty, kiln sites which produced black-gazed porcelain have been spread in Sichuan and Chongqing. For instance: Guangyuan kiln [4], Jinfeng kiln [5], Wagangba kiln [6], Xiba kiln [7], Suji kiln [8], Xirong kiln, Liulichang kiln [9], Dongbei kiln [10], Tushan kiln [11], Rongchang kiln [12] and so on. The black-gazed porcelain from these kiln sites were in similar appearance. Particularly, the porcelain from those kilns which were dominated in producing the black-gazed porcelain like Guangyuan kiln, Tushan kiln, Xiba kiln, Rongchang kiln etc. were of high similarity both in species and material. In the meantime, because of the compact black body, Jianzhou teacalix were too heavy for long distance transportation. Moreover, raw material of high quality was in decline. The duplicate with a lower quality and price appeared in the market from place to place, which resulted in the phenomenon of "bad money drives out good money", and the decline of Jianzhou kiln.

In Song dynasty, Sichuan is a crucial place for tea, which partly prevailed the habit of drinking tea, and further boosted the needs of black-gazed tea-calix. From the archaeological findings, Sichuan has both local porcelain as well as famous ones from other places with rich types. In mid-August of 2012, Chengdu Cultural Relics and Archaeology Research Institute began to excavate in the relics in the northeast of Chengdu Tianfu Square. Numerous cultural relics have been unearthed here, among which porcelain has taken up a great number. Particularly, there existed many black-gazed porcelains with complex origins and unique decorations. From the unearthed Song black-gazed porcelain, the tea-calix enjoyed a numerous number. The author has divided it into Jianzhou kiln, Jizhou kiln and Guangyuan kiln. And the author further found that local porcelain is mainly regarded as from Guangyuan kiln while products from other places are mainly regarded as from Jianzhou kiln. But there still existed a lot of uncertainties which need to be further discussed.

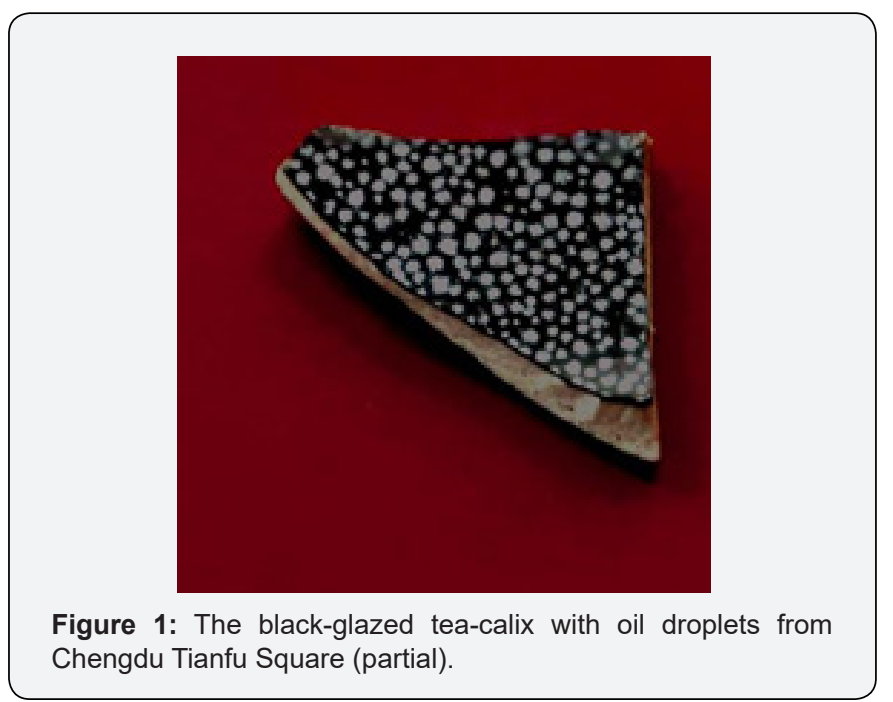

Sample 2012CTDTN02W02(3):1, with a height of $4.3 \mathrm{~cm}$, a refined body and black glaze decorated by silver oil droplets, has been classed as Type C Jian kiln tea-calix in the published Report of Archaeological Excavation at the Ancient Ruins of Northeastern Tianfu Square, Chengdu [R] by the author. But there existed no related report in the kiln of Shuiji town, Jinyang city [13]. On the contrary, it is the northern kiln as Ding kiln, Hebi kiln and Huairen kiln where could find the similar tea-calix. In December 2016, the author was lucky to get a piece of an incomplete porcelain bowl which enjoyed a high similarity with Sample 2012CTDTN02W02(3):1 by visual inspection, and the author did further professional scientific research on it (Figures $1 \& 2)$.

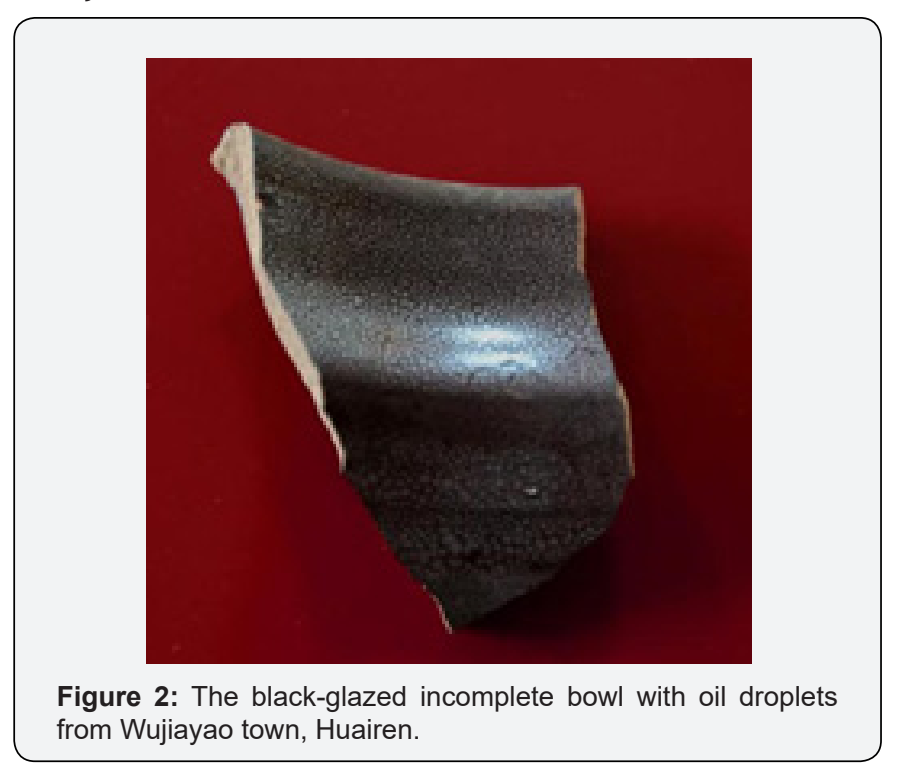

Analysis Methods and Condition

\section{Digital Versatile Microscope}

The author micro examined the former two samples' body and glaze by VHX-5000 digital versatile microscope produced by Keyence Company of Japan.

\section{Elemental Analysis}

The author analyzed the former two samples' glaze by M4 TORNADO XRF produced by Bruker Company of Germany.

Analysis condition of the major chemical component:

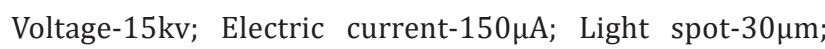
testing time-200s.

Analysis condition of the trace chemical component $\left(\mathrm{Rb}_{\backslash} \mathrm{Sr}_{\backslash}\right.$ Y, $\mathrm{Zr})$ :

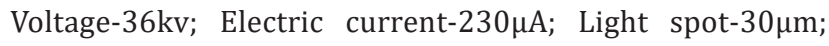
testing time-200s.

Analysis condition of the mapping:

Voltage-50kv; Electric current-800 $\mu$ A; Light spot-30 $\mu \mathrm{m}$. 


\section{Global Journal of Archaeology \& Anthropology}

\section{Phase Composition Analysis}

The author analyzed the former two samples' body and glaze by HR Evolution Raman spectrometer produced by Horiba Company of Japan.

Analysis condition:

Wave length of laser device-532nm and 785nm;

Laser power- $2 \mathrm{~mW}$;

Object glass-50X LWD.

Results and Analysis

Digital Versatile Microscope
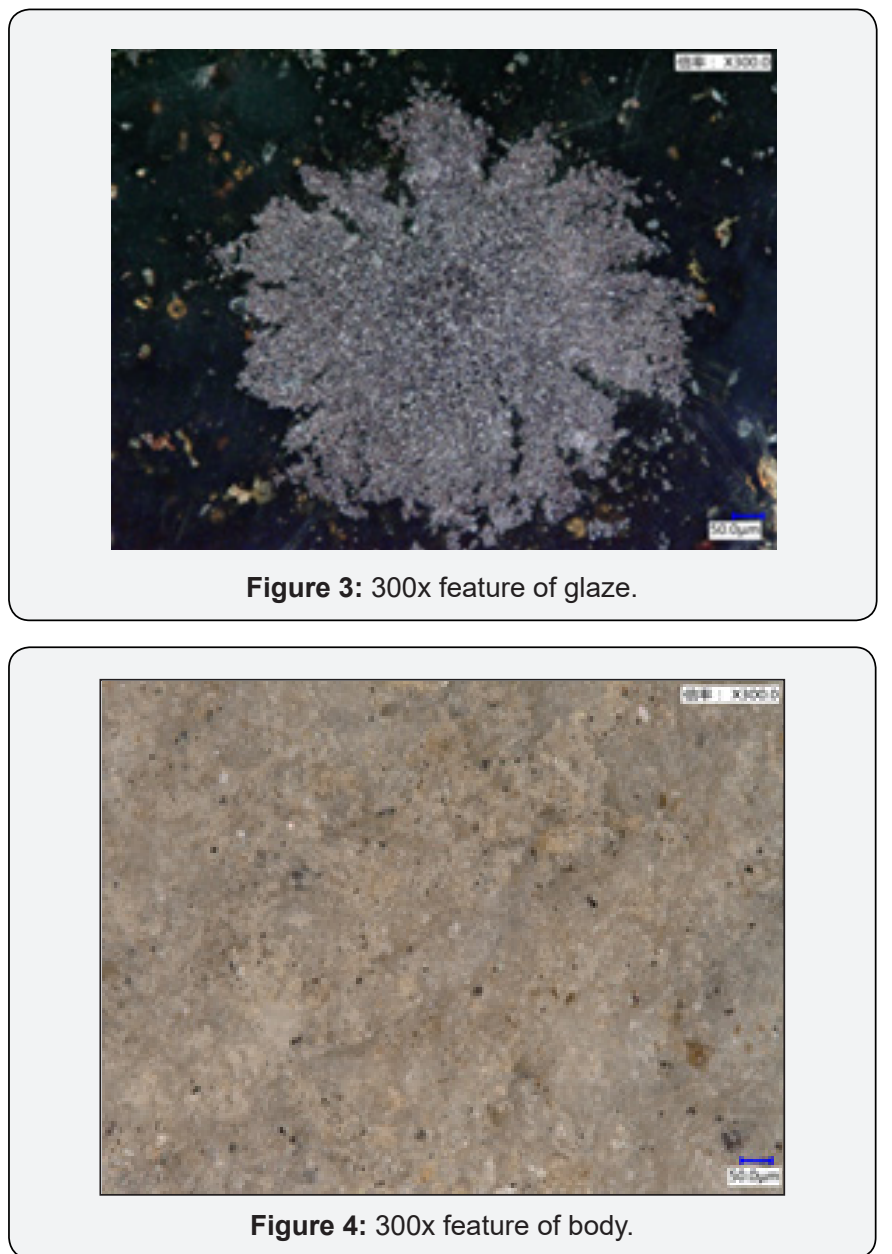

Figures $3 \& 4$ are 300x feature of glaze and body, from which we can see tawny particulate matter irregularly distributed Table 1: The major chemical components of the black-glazed porcelain with oil droplets (wt \%).

\begin{tabular}{|c|c|c|c|c|c|c|c|c|c|c|c|}
\hline \multicolumn{1}{|c|}{ Origin } & Position & $\mathbf{N a}_{\mathbf{2}} \mathbf{0}$ & $\mathbf{M g O}$ & $\mathbf{A l}_{2} \mathbf{O}_{\mathbf{3}}$ & $\mathbf{S i O}_{\mathbf{2}}$ & $\mathbf{K}_{\mathbf{2}} \mathbf{0}$ & $\mathbf{C a O}$ & $\mathbf{T i O}_{\mathbf{2}}$ & $\mathbf{M n O}$ & $\mathbf{F e}_{\mathbf{2}} \mathbf{O}_{\mathbf{3}}$ & $\mathbf{P}_{\mathbf{2}} \mathbf{0}_{\mathbf{5}}$ \\
\hline Chengdu Tianfu Square & black-glaze & 1.2 & 2.07 & 13.49 & 67.22 & 4.1 & 4.6 & 1.07 & 0.14 & 5.97 & 0 \\
\hline Huairen Wujiayao town & black-glaze & 1.39 & 1.98 & 14.56 & 65.87 & 4.09 & 4.72 & 1.02 & 0.12 & 6.17 & 0 \\
\hline Chengdu Tianfu Square & silver oil droplets & 1.03 & 2.09 & 13.55 & 53.98 & 4.15 & 5.31 & 1.88 & 0.21 & 17.42 & 0 \\
\hline Huairen Wujiayao town & silver oil droplets & 0.97 & 2.12 & 14.91 & 53.24 & 4.13 & 5.6 & 1.69 & 0.2 & 16.86 & 0 \\
\hline
\end{tabular}

\section{Analysis Results}

The above data show that there exists high similarity between under the black glaze [14]. The oil droplets are bright silver crystalline, which are apparently higher than the black glaze. And both body of the sallowish samples are pure and smooth, with black particulate matter distributed, which made it hard to distinguish the two samples.

\section{The Chemical Component of the Glaze}
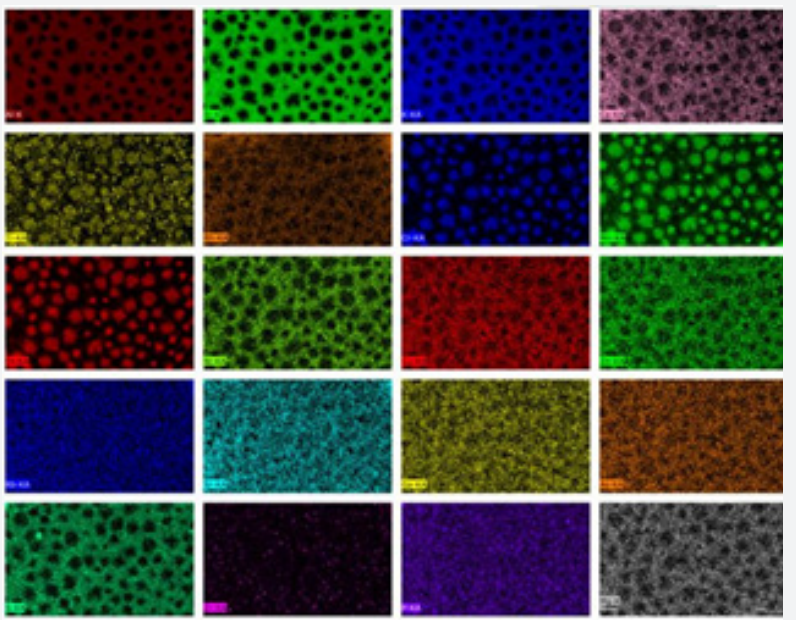

Figure 5: The distribution of the chemical components of the lack-glazed porcelain droplets with oil.

The glaze of porcelain is composed of clay + fluxing medium (ash admixture / feldspar) or clay + fluxing medium (ash admixture / feldspar) + quartz. But it is hard to define the origin of the trace element component. Thus, there exist great complexity and regional variety in its origin. However, it brings far more accuracy to judge the origins of the porcelain by its trace element component. Being a kind of rare and ancient porcelain, the blackglazed porcelain with oil droplets is bound to have a precise formula. When diagnose the chemical component of the glaze, the trace element component should be given to the priority and refer to the major chemical component as well. Tables $1 \& 2$ list the data of the major chemical component and the trace element component. Table 3 lists the chemical compositions of black glaze in Jianzhou kiln, Jizhou kiln, Junzhou kiln-like and Cizhou kiln. The distribution of the chemical components of the glaze can be seen from microscopic view and can further prove the craftsmanship, which has a far more significance on researching the black-glazed porcelain with oil droplets. Figure 5 presents the distribution of the chemical components of the black-glazed porcelain with oil droplets. 


\section{Global Journal of Archaeology \& Anthropology}

in Huairen Wujiayao town. Particularly, the ratio between $\mathrm{Rb}$, Sr, Y and Zr largely matches with its each absolute content. It's easy to find out the obvious difference between porcelain in Jianzhou kiln, Jizhou kiln, Junzhou kiln-like, and Cizhou kiln when compared the major chemical components of it.

Table 2: The trace element components of the glaze of black porcelain $(\mathrm{ppm}<\mu \mathrm{g} / \mathrm{g}>$ ).

\begin{tabular}{|c|c|c|c|c|c|}
\hline Origin & Position & Rb & Sr & Y & Zr \\
\hline Chengdu Tianfu Square & black-glaze & 227 & 413 & 37 & 342 \\
\hline Huairen Wujiayao town & black-glaze & 192 & 497 & 43 & 438 \\
\hline Chengdu Tianfu Square & $\begin{array}{c}\text { silver oil } \\
\text { droplets }\end{array}$ & 347 & 722 & 83 & 673 \\
\hline Huairen Wujiayao town & $\begin{array}{c}\text { silver oil } \\
\text { droplets }\end{array}$ & 306 & 797 & 67 & 737 \\
\hline
\end{tabular}

\section{Analysis of Phase Composition}
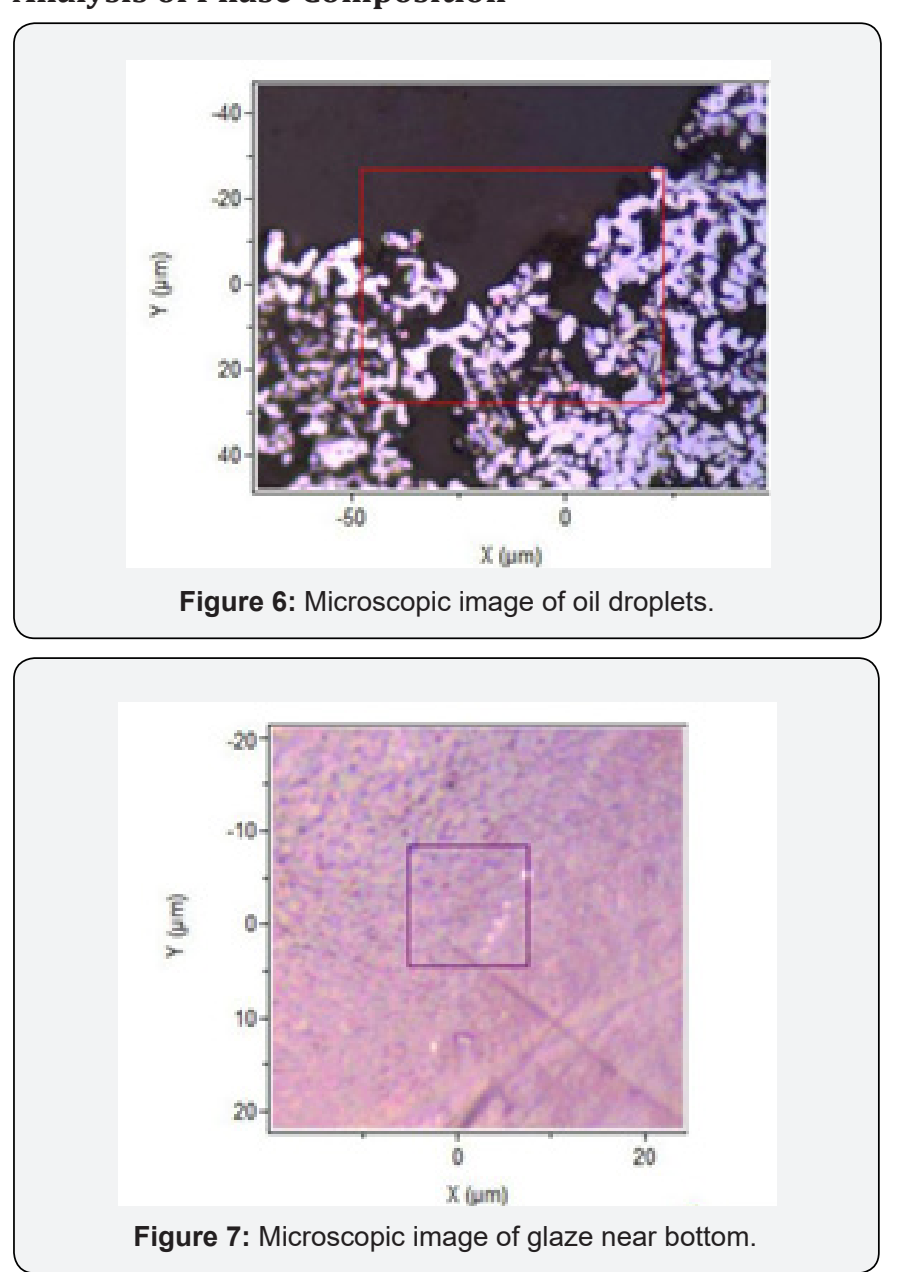

According to the results of XRF analysis, the black-glazed porcelain with oil droplets holds a high quantity of Fe, belonging to high-temperature iron glaze, which indicates that Fe plays an important role in the appearance of oil droplets. The Raman results are as follows, Figures $6 \& 7$ are microscopic image, Figures $8 \& 9$ are Raman image, and Figure 10 is result of phase composition.
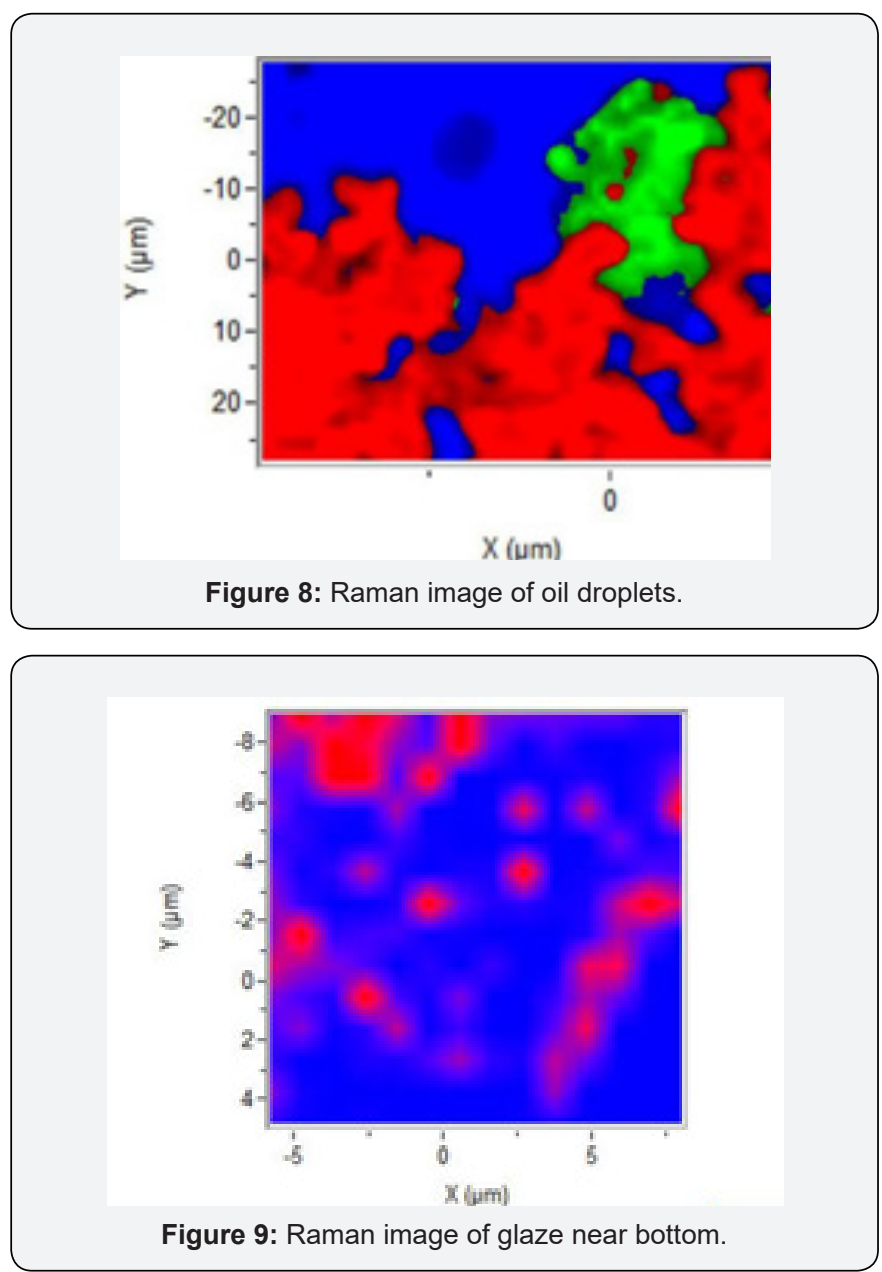

\section{Analysis of Glaze}

According to the results of mapping, there existed 4 kinds of ingredients here. After compared with the statistics in database, the red zone is mainly composed of $\mathrm{Fe}_{2} \mathrm{O}_{3}$, but there appears a Raman band on $654 \mathrm{~cm}^{-1}$, which should be $\mathrm{Fe}_{3} \mathrm{O}_{4}$. Thus, the red zone should be composed of both $\mathrm{Fe}_{2} \mathrm{O}$ and $\mathrm{Fe}_{3} \mathrm{O}_{4}$. The blue zone is composed of $\mathrm{SiO}_{2}$. The orange zone is largely composed of C. And the green zone remains unknown, because it cannot be easily to observed by the microscope. The above 2 samples both contain $\mathrm{Fe}_{2} \mathrm{O}_{3}, \mathrm{Fe}_{3} \mathrm{O}_{4}$, and $\mathrm{C}$, these 3 ingredients are not isolated, but would transform while firing the ceramics:

$$
\begin{aligned}
& 2 \mathrm{Fe}_{2} \mathrm{O}_{3}+3 \mathrm{C}=4 \mathrm{Fe}+3 \mathrm{CO}_{2} \text { (condition: high temperature) } \\
& 3 \mathrm{Fe}+2 \mathrm{O}_{2}=\mathrm{Fe}_{3} \mathrm{O}_{4} \text { (condition: firing) }
\end{aligned}
$$

Thus, high amount of $\mathrm{TiO}_{2}$ in 2 samples transforms $\mathrm{Fe}_{2}{ }_{2}$ into $\mathrm{Fe} 3+$, which means it transforms spare $\mathrm{Fe}_{3} \mathrm{O}_{4}$ into $\mathrm{Fe}_{2} \mathrm{O}_{3}$ [15]. However, there contains $\mathrm{C}$ in both 2 samples indicating that the above transform suddenly stops while firing the ceramics. As a result, the high amount of $\mathrm{TiO}_{2}$ and the existence of $\mathrm{C}$ and $\mathrm{Fe}_{3} \mathrm{O}_{4}$ be the unique identification with other porcelain.

\section{Conclusion}

In general, compared with the 2 samples with the help of 


\section{Global Journal of Archaeology \& Anthropology}

digital versatile microscope, XRF and Raman spectrometer, it is shown that there enjoys a high similarity between 2 samples which belong to a same origin [28]. The shape of the blackglazed tea-calix with oil droplets holds a high similarity with the tea-calix with oil droplets of Huairen kiln in Jin dynasty collected

Table 3: The Chemical Compositions of Black Glaze in some parts of china (wt \%) ${ }^{\text {xiv }}$

\begin{tabular}{|c|c|c|c|c|c|c|c|c|c|c|}
\hline Sample & $\mathbf{N a}_{\mathbf{2}} \mathbf{O}$ & $\mathbf{M g O}$ & $\mathbf{A l}_{\mathbf{2}} \mathbf{O}_{\mathbf{0}}$ & $\mathbf{S i O}_{2}$ & $\mathbf{K}_{\mathbf{2}} \mathbf{O}$ & $\mathbf{C a O}$ & $\mathbf{T i O}_{2}$ & $\mathbf{M n O}_{\mathbf{0}}$ & $\mathbf{F e}_{\mathbf{2}} \mathbf{O}_{\mathbf{3}}$ & $\mathbf{P}_{\mathbf{2}} \mathbf{O}_{\mathbf{5}}$ \\
\hline $\begin{array}{c}\text { Black-glazed porcelain of Jianzhou kiln in } \\
\text { Northern Song dynasty jy2 }\end{array}$ & 0.08 & 1.44 & 17.81 & 62.72 & 2.6 & 5.81 & 0.68 & 0.46 & 6.76 & 1.13 \\
\hline $\begin{array}{c}\text { Black-glazed porcelain of Jianzhou kiln in } \\
\text { Northern Song dynasty jy3(silver-glazed) }\end{array}$ & 0.06 & 1.87 & 18.88 & 59.62 & 3.43 & 5.85 & 0.53 & 0.93 & 6.74 & 1.9 \\
\hline $\begin{array}{c}\text { Black-glazed porcelain of Jizhou kiln in Song } \\
\text { dynasty }\end{array}$ & 0.38 & 2.98 & 13.51 & 61.49 & 4.73 & 8.76 & 0.78 & 0.91 & 5.2 & 1.55 \\
\hline $\begin{array}{c}\text { Black-glazed porcelain of Junzhou kiln-like } \\
\text { in Tang dynasty BY-hy1 }\end{array}$ & 0.63 & 2.19 & 14.59 & 63.24 & 2.78 & 8.43 & 0.81 & 0.18 & 5.59 & 0.63 \\
\hline $\begin{array}{c}\text { Black-glazed porcelain of Cizhou kiln in } \\
\text { Yuan dynasty }\end{array}$ & 0.33 & 1.85 & 17.41 & 63.12 & 3.84 & 6.11 & 0.6 & 0.34 & 5.26 & 0.77 \\
\hline
\end{tabular}

Note: The Data takes the average of 5 points.

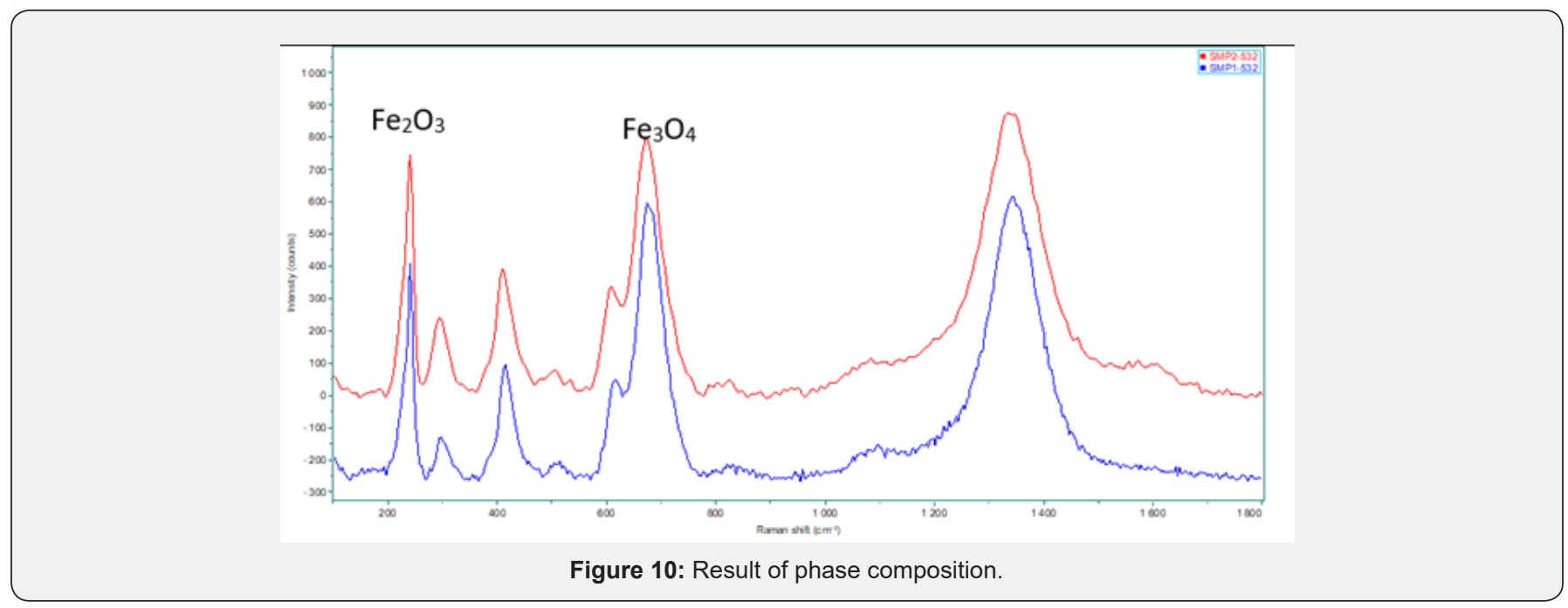

Figure 10: Result of phase composition.

in Shanxi Museum (height: $4.5 \mathrm{~cm}$; rim diameter: $9 \mathrm{~cm}$; bottom diameter: $2.9 \mathrm{~cm}$; Figures $11 \& 12$ ), which indicates that these 2 samples belong to a same age, in other words, this black-glazed tea-calix with oil droplets was definitely from Huairen kiln of Shanxi in Jin dynasty.

Note: The Data takes the average of 5 points.

Figure 11: The tea-calix with oil droplets of Huairen kiln in Jin dynasty collected in Shanxi Museum, China.

Discussion

There remain no records of porcelain of Huainren kiln that was excavated in Sichuan area, which suggests that it holds a high reputation in the Chinese porcelain history. Moreover, it further indicates that there existed "a porcelain road" which bridged northern and southern China during war period of Song and Jin dynasties. And it provides enough scientific evidences

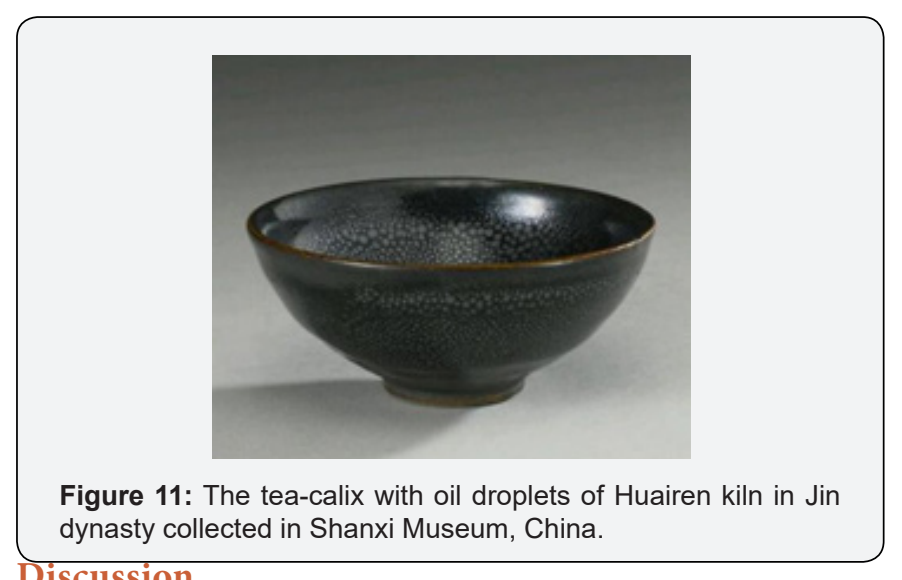

for the research of trade and culture between Southern Song Dynasty and Jin Dynasty. Natural scientific technology is increasingly applied to the research and conservation of cultural relics. This paper is an attempt under the guidance of scientific technology, and the author wishes that there could be found more archaeological materials for further research.

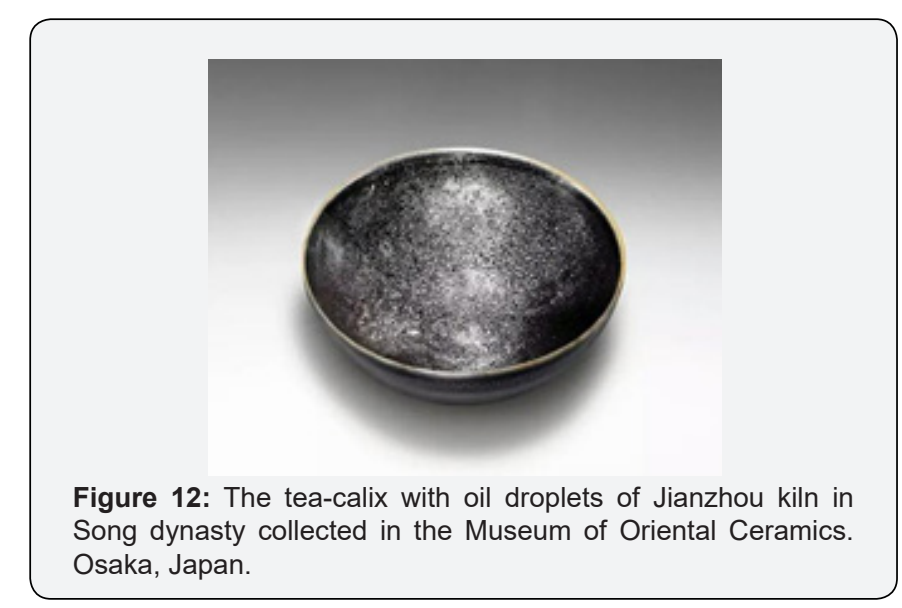




\section{Acknowledgment}

This paper was financially supported by Zhejiang Provincial Heritage Protection Technology Projects (2017020\&2018018); Ningbo Project of Cultivating Promising Personnel in Cultural and Art Area (2017-2020).

\section{References}

1. Du Jingnan (2015) Study on provenance of Kraak porcelains from "Nan'ao I" shipwreck [J]. Spectroscopy and Spectral Analysis, 6: 17461750.

2. Xie jin (2017) Shanxi region collection kiln porcelain of song and jin Dynasty technology research[D]. Shanxi university, China.

3. Zhang Yun (2016) The blue-and-white porcelains with "Dianshansuo"mark of the Prince Qin. Journal of Northwest University (Natural Science Edition), China, 6: 932-936.

4. Sichuan Provincial Institute of cultural relics and Archaeology (2003) Guangyuan cultural relics protection and Management Institute. brief report on the excavation of Guangyuan Ciyaopu kiln relics[R]. Sichuan Cultural Relics, China, 3: 3-21.

5. Chengdu Institute of cultural relics and Archaeology (2000) Dujiangyan Cultural relics Bureau. Excavation report of Jinfeng kiln in Dujiangyan city[R]. Archaeological discoveries in Chengdu. Beijing, China, pp. 223.

6. Chengdu Institute of cultural relics and Archaeology (2011) Dujiangyan Cultural relics Bureau. Excavation report of Jinfeng wagangba kiln in Dujiangyan city[R]. Archaeological discoveries in Chengdu. Beijing, China, pp. 264.

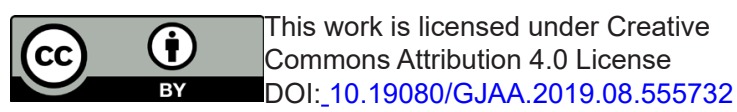

7. Chen Liqiong (2001) Investigation of the ancient kiln in Leshan City[R]. The study of ancient ceramics. Chongqing press, Chongqing, China.

8. Chen Liqiong (2001) Investigation of the ancient kiln in Leshan City[R]. The study of ancient ceramics. Chongqing press, Chongqing, China.

9. Chengdu Institute of cultural relics and archaeology (2010) Chengdu Liulichang ancient kiln 2010 trial excavation of the Chengdu archaeological discovery report [R]. Beijing, China, pp. 352.

10. Mo Honggui (1984) Ancient kiln found in Pujiang county[J]. Sichuan ancient ceramics research (II). Sichuan Academy of Social Sciences Press, Chengdu, China, pp. 227.

11. Chongqing Institute of cultural relics and archaeology (2001) Chongqing Tu Shan kiln [R]. Science Press, Beijing, China.

12. Chen Liqiong, Dong Xiaochen (2010) Three Gorges and Chinese porcelain [M]. Chongqing press, Chongqing, China, pp. 105.

13. Jianzhou kiln Archaeological team (1995) Archaeological excavation report of Fujian Jianyang Shuiji town kiln site 1991 1992 [R]. Archaeology. Zengfan (1996) New archaeological discovery of Jianzhou kiln [J]. cultural relics, Song Boyin. Survey record of Jianzhou kiln [R]. cultural relics survey reference, China.

14. Xiong Yingfei (2012) Coloring of the high-fired iron glaze of ancient Chinese ceramics[J]. Sciences of Conservation and Archaeology, 1: 4551.

15. Ishii Tsuneshi (1930) Experiments on the tenriuji yellow celadon glaze [J]. Transactions of British ceramicsociety.Wedgwood bi-cen-tenary Memorial number, pp. 360-387.

\section{Your next submission with Juniper Publishers will reach you the below assets}

- Quality Editorial service

- Swift Peer Review

- Reprints availability

- E-prints Service

- Manuscript Podcast for convenient understanding

- Global attainment for your research

- Manuscript accessibility in different formats

( Pdf, E-pub, Full Text, Audio)

- Unceasing customer service

Track the below URL for one-step submission https://juniperpublishers.com/online-submission.php 